\title{
O trabalho docente no atendimento educacional especializado: a apreensão das representações sociais
}

\section{The teaching work of specialized educational care: the seizure of social representations}

\author{
Arlete Marinho Gonçalves \\ Universidade Federal do Pará (UFPA)
}

\begin{abstract}
RESUMO: O Estudo tem como objetivo apreender as representações sociais de professores sobre o trabalho docente dos que atuam na educação especial. $O$ estudo se fundamentou na Teoria das Representações Sociais de abordagem Estrutural. Os dados foram produzidos com 32 docentes. Utilizou-se o questionário e a técnica de associação livre. Para o tratamento dos dados foi utilizado o software EVOC 2002. O Núcleo Central evidenciou as "relações de afeto" e "comprometimento docente", ancorados nas evocações "paciência, compreensão e responsabilidade". Conclui-se que os docentes que trabalham no atendimento do público alvo da educação especial tem como principio a relação de compromisso e responsabilidade voltada para o respeito ao diferente e ao seu tempo de aprender.
\end{abstract}

PALAVRAS-CHAVE: Atendimento Educacional Especializado. Teoria das Representações Sociais. Trabalho Docente.

ABSTRACT: The study aims to seize the social representations of teachers on the teaching work of those who work in special education. The study was based on the theory of social representations of structural approach. The data were produced with 32 teachers. The questionnaire was used and the technique of free association. For the treatment of the data was used EVOC 2002 software. The core showed the "relations of affection" and "teaching commitment", anchored in the evocations "patience, understanding and responsibility." It is concluded that teachers working in the target audience of special education has as its principle the commitment and responsibility toward respect for the different and your time to learn.

KEYWORDS: Specialized Educational Service. Theory of Social Representations. Teaching Work.

\section{Introdução}

No Brasil, o atendimento às pessoas com deficiência, transtornos globais do desenvolvimento e superdotação têm início no século XIX e XX, por meio da criação de instituições especializadas para esse público, são elas: o Imperial Instituto dos Meninos Cegos (1854); o Instituto dos Surdos Mudos (1857), ambos no Rio de Janeiro; o Instituto Pestalozzi (1926); Associação de Pais e Amigos dos Excepcionais - APAE (1954); e, atendimento aos Superdotados na Sociedade Pestalozzi, por Helena Antipoff (1945).

No ano de 1973, o Ministério da Educação criou o Centro Nacional de Educação Especial, denominado CENESP, órgão responsável pela coordenação da educação 
especial no Brasil, no entanto apresentava ainda uma filosofia integracionista, "configuradas por campanhas assistenciais e iniciativas isoladas do Estado" (BRASIL, 2008, p.2). Assim sendo, podemos afirmar que nesse período, não havia de fato uma política pública educacional que estivesse aberta à garantia de direitos iguais no que diz respeito à educação de todos de forma gratuita e no ensino regular de ensino.

A partir do final do século XX, avançam as políticas educacionais no Brasil, relacionadas à educação especial na perspectiva da inclusão. Um dos documentos mais importantes está presente na Lei de Diretrizes e Bases da Educação Nacional 9394/96 nos artigos 58, 59 e 60, a qual determina que a matrícula dos Educandos com deficiência, transtornos globais do desenvolvimento e superdotação deverá ser realizada preferencialmente na rede regular de ensino, com metodologias diferenciadas, professores qualificados, atendimento educacional especializado e adaptação curricular.

Nesse sentido, o professor da sala de aula se torna um dos sujeitos da escola que passa a ter entre suas responsabilidades se qualificar e receber esse aluno, no intuito de atender as suas especificidades, sejam elas deficiências, transtorno global do desenvolvimento ou superdotação. Junto ao professor da sala de aula, outro profissional ganha destaque nesse trabalho, o professor do Atendimento Educacional Especializado que tem como objetivo complementar ou suplementar a aprendizagem dos alunos público alvo da educação especial.

Nesse sentido o atendimento educacional especializado é compreendido como um "conjunto de atividades, recursos de acessibilidade e pedagógicos organizados institucional e continuamente" (BRASIL, 2011). O público alvo da educação especial, segundo a Resolução no 4 de 2009, são:

I - Alunos com deficiência: aqueles que têm impedimentos de longo prazo de natureza física, intelectual, mental ou sensorial. II - Alunos com transtornos globais do desenvolvimento: aqueles que apresentam um quadro de alterações no desenvolvimento neuropsicomotor, comprometimento nas relações sociais, na comunicação ou estereotipias motoras. Incluem-se nessa definição alunos com autismo clássico, síndrome de Asperger, síndrome de Rett, transtorno desintegrativo da infância (psicoses) e transtornos invasivos sem outra especificação. III - Alunos com altas habilidades/superdotação: aqueles que apresentam um potencial elevado e grande envolvimento com as áreas do conhecimento humano, isoladas ou combinadas: intelectual, liderança, psicomotora, artes e criatividade (BRASIL, 2009). 
Com a crescente demanda acerca do trabalho docente efetivado pelo professor que faz o Atendimento Educacional Especializado (AEE) que tem como foco a inclusão educacional e garantia da acessibilidade nas escolas, o Grupo de Estudos e Pesquisas da Educação Especial (GEPEE) da Faculdade de Educação do campus de Breves - PA, da Universidade Federal do Pará, buscou analisar as representações sociais de professores do AEE do município de Breves-PA acerca do trabalho docente com os alunos público alvo da Educação Especial. Como específicos este estudo buscou identificar o perfil dos sujeitos e apreender o núcleo central e periférico das Representações Sociais dos professores do AEE sobre o trabalho docente.

\section{Metodologia}

A metodologia adotada para esta pesquisa foi o quanti-qualitativo. Os dados foram produzidos com 32(trinta e dois) professores do município de Breves - PA que aceitaram participar da pesquisa e assinaram o termo livre de consentimento de pesquisa. Para a coleta de dados utilizou-se o questionário sócio-demográfico com quatro questões fechadas e a técnica de associação livre de palavras, com a utilização da frase indutora: "trabalho docente com alunos público alvo da educação especial".

A técnica de associação livre de palavras é um tipo de investigação aberta que se "estrutura a partir da evocação de respostas dadas com base em um estímulo indutor, o que permite colocar, em evidência, universos semânticos relacionados a determinado objeto" (MACHADO; ANICETO, 2010).

O teste de Associação Livre de Palavras - ALP foi desenvolvido por Jung (RAPAPORT, 1965 apud NÓBREGA E COUTINHO, 2003), inicialmente usual na prática clínica. Atualmente também é utilizado nas pesquisas de cunho psicossocial, nas apreensões das Representações Sociais. Nessa direção "é uma técnica projetiva elaborada para trazer à consciência, elementos inconscientes por meio das manifestações de condutas e reações, do sujeito sobre determinado objeto" (NÓBREGA; COUTINHO, 2003, p. 59). Então, a Associação Livre de Palavras é uma técnica para: 
Coletar os elementos constitutivos do conteúdo de uma representação [...] consiste em se pedir aos sujeitos que, a partir de um termo indutor apresentado pelo pesquisador, digam as palavras ou expressões que lhes tenham vindo imediatamente à lembrança (ABRIC, 1994, p. 66)

Nessa via, utilizamos a expressão indutora desta pesquisa: Trabalho docente com alunos público alvo da Educação Especial, o qual deveria ser respondido com palavras soltas, sem formar frases num período determinado de 1 ( um minuto). Esse tempo foi necessário para dar maior validação aos resultados da pesquisa. Ao término, solicitou-se a cada docente que enumerasse as evocações por ordem de importância.

Para o tratamento dos dados, criou-se um banco de dados com as variáveis fixas e as de opinião dos sujeitos participantes da pesquisa, que foram processados e analisados através do programa computacional EVOC 2002 de forma descritiva e interpretativa. O programa, facilitou na apreensão do Núcleo central e periférico das representações sociais dos profissionais que trabalham no AEE acerca de seu trabalho com alunos público alvo da educação especial.

\section{- Representação social e abordagem estrutural}

A Teoria das Representações Sociais (TRS) teve seu início com as pesquisas de Moscovici em 1961. A TRS é considerada como um conjunto de conceitos, afirmações, explicações, consideradas verdadeiras teorias do senso comum, ciências coletivas pelas quais se procede a interpretação e mesmo a construção das realidades sociais advindas do cotidiano (MOSCOVICI, 2003).

Assim sendo, as representações sociais constituem elementos essenciais para a análise dos mecanismos que interferem na eficácia do processo educativo e nas políticas educacionais que se implementam no cotidiano escolar. Vale destacar, que a TRS cresce a cada ano nas diferentes áreas do conhecimento.

A partir da grande teoria moscoviciana, surgem outras ramificações dessa teoria, são elas: a abordagem societal (DOISE, 1995), a abordagem estrutural (ABRIC, 2000) e a abordagem dimensional ou processual (JODELET, 2001). Todas elas são matrizes que podem se articular, uma vez que são frutos da grande teoria de Moscovici (SÁ, 1998).

A partir dos objetivos propostos neste artigo, fizemos a opção pela abordagem complementar das Representações Sociais, denominada estrutural. Jean-Claude Abric 
elaborou essa abordagem complementar a partir da ideia de que toda representação social tem um Núcleo Central.

A abordagem estrutural, foi proposta pela primeira vez dentro do quadro de pesquisa experimental, em 1976, por meio da tese de doutoramento de Abric, denominada Jeux, conflits et representations sociales, na Universidade de Província. O autor formulou a partir dos seguintes termos:

[...] a organização de uma representação apresenta uma característica particular: não apenas os elementos da representação são hierarquizados, mas, além disso, toda representação é organizada em torno de um Núcleo Central, constituído de um ou de alguns elementos que dão à representação o seu significado (ABRIC, 1994, p.119 apud SÁ, 2002, p.62).

Os objetivos básicos dessa teoria indicam que as RS possuem uma organização com características específicas e uma hierarquização dos elementos que se estruturam em torno de um Núcleo Central (NC), constituído de um ou mais elementos que dão à representação um significado.

Sendo assim, o Núcleo Central aponta para funções, sendo uma geradora e outra organizadora. Segundo Sá (2002, p.73), “a ideia essencial da teoria é que toda representação está organizada em torno de um núcleo central, que determina ao mesmo tempo sua significação e sua organização interna". Ele pode ser determinado pela natureza do objeto representado ou pela relação que o sujeito ou o grupo mantêm com tal objeto (GONÇALVES, 2012).

O NC define a homogeneidade de um grupo social, sendo determinado pela história desse grupo e ligado à sua memória coletiva, bem como, pelo sistema de normas. Uma vez normativo, é resistente à mudança, e sua função primordial é garantir a continuidade da representação, cuja "ausência desestruturaria a representação ou lhe daria uma significação complementar diferente" (ABRIC, 2000, p.73).

Para dar sustentação ao NC necessita de elementos complementares que provocam essa resistência. Esses elementos são denominados por Abric e Flament como "núcleo periféricos" ou "periferia das representações sociais". Sendo assim, ligado à ideia de centralidade, surge o conceito de sistema periférico, onde ocorrem atualizações e contextualizações da dimensão normativa. 
O sistema periférico quebra o consenso e remete a "representação à mobilidade, à flexibilidade e à expressão individualizada" (SÁ, 2002, p.73). Diante disso, Abric (2000) diferencia os dois sistemas, ao afirmar que o sistema central é normativo e o sistema periférico é funcional. Significa dizer que é a partir da periferia que uma representação pode se ancorar na realidade do presente.

Segundo Sá (2002), o sistema periférico como complementaridade do Núcleo Central possui as seguintes funções: a concretização do Sistema Central, mais sensível e determinado pelas características do contexto imediato; a regulação e adaptação do NC, que tem como ação mapear os constrangimentos e as características de situações à qual o grupo se encontra confrontado, além de defender e proteger a significação central da representação; e a flexibilidade e elasticidade, o que liga a representação das variáveis individuais interligadas à história, experiências e o vivido de cada sujeito, permitindo, assim, a elaboração de "representações sociais individualizadas" organizadas em torno de um NC comum.

\section{Resultados e discussão}

Obtivemos um perfil dos sujeitos com a faixa etária de mais de 30 anos de idade (79\%) dos professores, prevalecendo com $83 \%$ o gênero feminino. Do total, $44 \%$ desses participantes possuem a formação no magistério com um tempo equivalente de 1 a 8 anos no exercício da profissão. Dos professores que aceitaram participar da pesquisa, integram o atendimento Educacional Especializado 96\%, os demais trabalham com alunos público alvo da educação especial apenas no ensino regular.

Esse perfil apresentado significa obter um conjunto de docentes relativamente adultos em sua maioria ainda prevalecendo o gênero feminino, ainda na formação inicial, dado extremamente preocupante para tratar melhor da questão do trabalho conduzido por esses sujeitos.

A associação livre de palavras nos proporcionou listar 127 palavras, destas, 66 eram diferentes. Foi possível observamos que as palavras "compromisso" e "paciência" emergiram com o maior número de evocações ( 7 cada), enquanto 39 palavras foram evocadas pelos participantes da pesquisa apenas uma vez.

A partir do uso do Software EVOC 2002 foi possível observarmos a distribuição das palavras por ocorrência em quatro casas ou quadrantes. Por meio desses quadrantes 
nos permitiram visualizar o Núcleo Central (NC) e a periferia das Representações Sociais. Para interpretar os quadrantes das RS, nos ancoramos em Oliveira, Marques e Tosoli (2005) que ressaltam a organização da leitura do NC e periférico das RS.

Assim, procedemos da seguinte leitura: no quadrante superior esquerdo, estão localizadas as palavras que constituem o NC das representações sociais; no quadrante superior direito, a primeira periferia; no quadrante inferior esquerdo, a segunda periferia e, por último, no quadrante inferior direito, a periferia distante das RS.

No NC, estão localizados os elementos centrais: "compreensão, paciência e responsabilidade". Já os elementos periféricos da representação social acerca do trabalho docente no AEE foram distribuídos nas três periferias: $1^{\mathrm{a}}$ periferia, com as palavras "amizade, compromisso, respeito e superação"; na $2^{\mathrm{a}}$ periferia, as palavras “família e inclusão"; e, na periferia distante estão localizadas as palavras: "acessibilidade, amor, conhecimento, cuidado, dedicação e dificuldade".

Esquema 1: Núcleo Central e periférico das RS acerca do trabalho dos profissionais do Atendimento Educacional Especializado

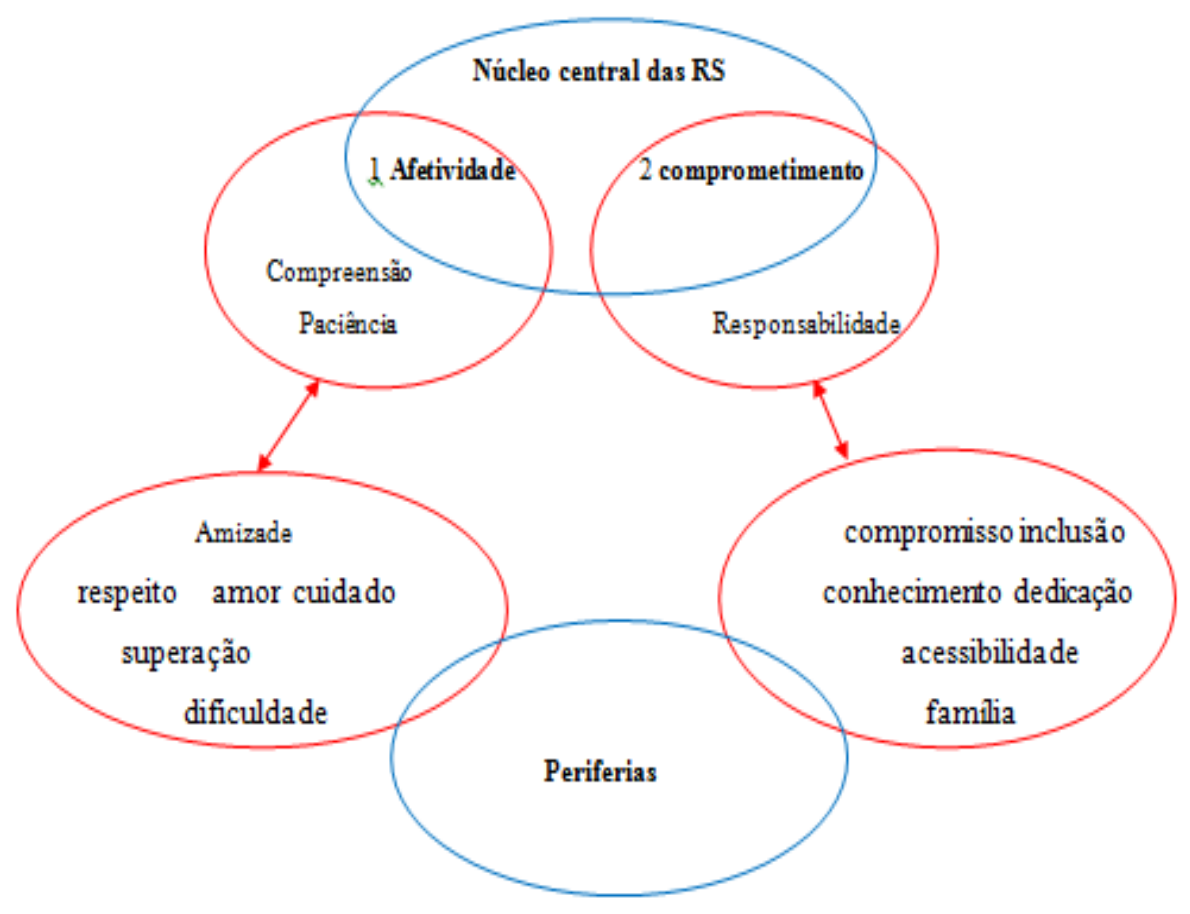

Autor: Ivete Marinho 
A partir dessa estrutura organizacional das RS, constatamos que compõem o núcleo central das representações as categorias validadas no conjunto das evocações: afetividade e comprometimento, ancorados nas palavras paciência, compreensão e responsabilidade. Essa organização se sustenta pelas periferias das RS que geram valor e credibilidade ao Núcleo Central.

\subsection{Afetividade}

A categoria afetividade, primeira categoria, é constituída das palavras centrais "paciência e compreensão", sustentadas pelas evocações "amizade, respeito, amor, cuidado, superação, família e dificuldade".

Nesse sentido, o trabalho no atendimento de alunos público alvo da educação especial nas escolas do município de Breves apontam que estes têm em vista que trabalhar com alunos com deficiência, transtornos globais do desenvolvimento e superdotação/Altas habilidades requer primeiramente compreensão das diferenças de cada aluno atendido por esse serviço na escola.

Essa característica é uma das fundamentais para que o profissional do AEE possa buscar caminhos para que cada aluno supere as suas dificuldades enfrentadas no dia-a-dia do processo de escolarização. Por outro lado, requer a característica de ter muita paciência no ato de educar, pois trabalhar com as diferenças, antes de tudo requer o cuidado, doação, amizade, atenção e tempo destinado a pesquisa, ao estudo de novas tecnologias e construção de materiais alternativos complementares ou suplementares a esse público.

Nesse sentido, faz-se necessário, acima de tudo, trabalhar com amor. A realização do trabalho docente na perspectiva da inclusão não é tarefa fácil na visão dos professores do AEE. As diversas dificuldades apresentadas nesse processo em alguns momentos se tornam barreiras no ensino aprendizagem dos alunos, pois dependem das condições de trabalho, apoio da família e da sua própria formação para consolidar o trabalho complementar no contraturno.

Os professores possuem no seu dia a dia de trabalho, uma carga muito extensa de atividades realizada no AEE que se desenham no atendimento e na confecção de materiais acessíveis para cada aluno atendido e suas necessidades. Esse serviço se 
desdobra, porque como a maioria das construções são produtos de acessibilidade de alta ou baixa tecnologia a maioria dos professores leva esse serviço para casa.

Pensar na inclusão é ter essa característica profissional do afetivo-emocional, o que significa se preocupar com o outro e garantir o mínimo de acessibilidade possível para que os alunos público alvo da educação especial possam ser atendidos de forma complementar ou suplementar como estabelece a Lei 7.611/2011. Segundo Vygotsky (1994) é na relação interpsicológica e intrapsicológica que acontece o desenvolvimento da criança. Para ele:

Todas as funções do desenvolvimento da criança aparecem duas vezes: primeiro no nível social, e, depois no nível individual, primeiro entre pessoas e depois no interior da criança [...] todas as funções superiores originaram-se das relações reais entre indivíduos humanos. (p.75)

O autor dá destaque a importância da interelação mediada como ponto fundamental para o desenvolvimento das funções superiores. Dito isto, revela o quão é importante termos professores com ações na docência que possam ter características dessa natureza. Como podemos perceber, é necessário no trabalho docente com alunos público alvo da educação especial o reconhecimento de que é um trabalho que requer "cuidado" e "paciência", mas também é um espaço que precisa ter gotas de "amor" e "doação", que tem como fim a garantia da aprendizagem de cada sujeito atendido no AEE, respeitado a sua diferença.

\subsection{Comprometimento}

Para o comprometimento, segunda categoria levantada a partir das evocações "compromisso, conhecimento, dedicação, inclusão e acessibilidade" aparece a palavra "responsabilidade" ancorada a esse conjunto de evocações, que dá a sua significação, organização e sustentação ao Núcleo Central das RS acerca do trabalho docente.

A formação de professores é um processo que passa pelo "compromisso" da busca incansável do conhecimento. A qualidade de ensino não se faz apenas com conteúdos materiais e salas bem equipadas, mas antes, faz necessário que o educador em formação, tenha disponibilidade, dedicação, determinação, flexibilidade e vontade de ir ao encontro de novos conhecimentos e práticas pedagógicas que venha por 
valorizar não apenas seu profissionalismo institucional, mas que também o valorize enquanto pessoa dotada de criatividade e capacidade de se relacionar com outros indivíduos, sejam eles seus pares ou seus educandos com deficiência, transtornos globais do desenvolvimento ou superdotação.

Vale destacar que no cenário da inclusão, o trabalho docente não é fácil nem para o professor, por que antes de tudo, requer formação do professor para esse atendimento diferenciado e também, como afirmamos acima, gostar do que faz, com compromisso em educar e ensinar pessoas diferentes no tempo e no como aprender.

O comprometimento da família no ambiente escolar é de extrema relevância e faz total diferença no progresso do aluno na escola. A família é o ingrediente que a escola necessita para que as crianças possam vencer os desafios da aprendizagem de acordo com as suas necessidades específicas. Assim, a participação conjunta de professores e pais não apenas melhora a prática do trabalho docente como também ajuda na integração e inclusão dos alunos envolvidos nesse cenário.

Assim, trabalhar com a educação especial necessita de constante atualização ou formação para dar conta das dificuldades encontradas ao longo do processo solicitado aos professores para o atendimento das necessidades de cada aluno. Nesse sentido, respeitar as diferenças é dar a garantia de acessibilidade de cada aluno conseguir sem muitos atropelos, alcançar o domínio das linguagens, das artes e das ciências de forma geral.

Segundo Correia (2012), após a Política Nacional de Educação Especial na Perspectiva da Inclusão, as escolas e professores têm se deparado com duas frentes de desafios no atendimento do público alvo da educação especial. O primeiro está voltado para a garantia de acessibilidade para pessoas com deficiência física e o segundo para alunos que necessitam de acessibilidade de comunicação, no caso da Língua de sinais para surdos. Essas dificuldades perpassam pela falta de materiais, de adaptação de mobiliário e físico, assim como na formação dos professores em uma nova língua.

O domínio da Língua de Sinais é fundamental para garantir a acessibilidade de comunicação e informação para surdos. Sem essa fluência e domínio, as barreiras permanecem mesmo com a sala de recursos multifuncionais completa de materiais do tipo I e II, pois o principal não será correspondido - a comunicação em Libras. 
Sendo assim, é indiscutível o princípio de inclusão e da diferença como um direito humano e universal, contudo, devemos refletir como está se dando esse trabalho docente nesses espaços educativos e de que forma essa ação está garantindo de fato e de direito o atendimento necessário e adequado a cada aluno que dela faz uso, num curto espaço de tempo que eles passam no AEE.

O Decreto no 7.611 de novembro de 2011 que dispõe sobre a educação especial e o atendimento educacional especializado é mais uma política que dá mais ênfase a esse serviço implementado nas escolas regulares, cujo maior intuito é a garantia da política de inclusão ao público alvo da educação especial. Nesse decreto, formaliza os seguintes objetivos do AEE, no art. $3^{\circ}$ :

I -prover condições de acesso, participação e aprendizagem no ensino regular e garantir serviços de apoio especializados de acordo com as necessidades individuais dos estudantes;

II-garantir a transversalidade das ações da educação especial no ensino regular;

III-fomentar o desenvolvimento de recursos didáticos e pedagógicos que eliminem as barreiras no processo de ensino e aprendizagem; e IV-assegurar condições para a continuidade de estudos nos demais níveis, etapas e modalidades de ensino (BRASIL, 2011).

O Estatuto da pessoa com deficiência, Lei 13.146 de julho de 2015, conhecida como Lei Brasileira de inclusão reforça a necessidade da institucionalização do AEE no Projeto pedagógico da escola, assim como as adaptações acessíveis ao público alvo da educação especial. A novidade na nova lei, é a garantia do planejamento de estudo de caso para a elaboração de plano de atendimento do AEE e da usabilidade de outros recursos (BRASIL, 2015).

No que diz respeito à formação desses profissionais que atuam no AEE, a presente Lei, estabelece que os programas de formação inicial e continuada possam garantir práticas inclusivas para o atendimento de alunos público alvo da educação especial. Além disso, destaca que há a necessidade de "formação e disponibilização de professores para o atendimento educacional especializado, de tradutores e intérpretes da Libras, de guias intérpretes e de profissionais de apoio"(BRASIL, 2015).

Os achados levantados nas falas de cada docente e de maior frequência das palavras repetidas nos quadrantes revelam que trabalhar no AEE com o público alvo da 
educação especial é cobrado de cada professor maior responsabilidade, compromisso e respeito ao outro.

No que diz respeito ao trabalho executado pelos profissionais do AEE, a resolução $\mathrm{n}^{\circ} 4$ e a lei 7.611 de $2011^{1}$ estabelecem que é de competência dos professores que atuam na sala de recursos multifuncionais ou CAEE em conjunto com demais professores do ensino regular: Criar cronograma de atendimento dos alunos; Planejar e executar planejamento no intuito de identificar as necessidades educacionais específicas dos alunos, a definição dos recursos necessários e as atividades a serem desenvolvidas durante o ano letivo; e Organizar o tipo e o número de atendimentos aos alunos na sala de recursos multifuncionais.

Além dessas atividades, necessita acompanhar a funcionalidade e a aplicabilidade dos recursos pedagógicos e de acessibilidade na sala de aula comum; Orientar professores e pais sobre os recursos de acessibilidade utilizados pelo aluno; Ensinar e usar a tecnologia assistiva de forma a ampliar habilidades funcionais dos alunos (BRASIL, 2008).

\section{Considerações Finais}

As Representações dos professores do Atendimento educacional Especializado acerca do trabalho docente com alunos público alvo da educação especial revelou que a maioria dos profissionais que atuam com esses educandos necessitam de duas formas para dar conta do processo ensino aprendizagem: a afetividade e o comprometimento.

Essas duas características foram acentuadas com o desvelamento do Núcleo Central das RS quando traz como principais palavras à responsabilidade, a paciência e a compreensão. Todas elas sustentadas pelas evocações advindas das periferias. Nesse sentido, trabalhar com o público da educação especial não pode ser considerada como tarefa fácil, uma vez que requer habilidades e qualidades que estão para além da formação pedagógica da sala regular, uma vez que necessita trabalhar em prol de dar conta das diferenças individuais de cada aluno atendido nesse espaço.

O compromisso e o respeito, acompanhado da palavra superação dão sustentação a palavra "responsabilidade", presente no Núcleo Central, sendo estas, as evocações

\footnotetext{
${ }^{1}$ Esta lei revogou o Decreto $\mathrm{n}^{\circ} 6.571$ de 17 de setembro de 2008, considerado como um dos primeiros documentos que trouxeram a organização do AEE na sala regular de ensino.
} 
mais destacadas nas falas dos docentes sujeitos da pesquisa. Não queremos aqui frisar que na sala regular não precisa desses adjetivos, contudo na sala do AEE, está o maior comprometimento e cobrança da acessibilidade e continuidade dos estudos desses alunos, pois é nesse espaço que deverá ser garantido a comunicação alternativa e ampliada a essa clientela.

Nesse sentido, é reforçado pela palavra paciência e cuidado, uma vez que é um público diferenciado, cujo tempo de aprendizagem não pode ser igualado aos que estão no ensino regular. No entanto, esse é um espaço que traça como trabalho docente mais dedicação e doação no processo de ensino, pois nem sempre os resultados vem a curto prazo. Assim sendo, há urgência desses profissionais estarem sempre em formação continuada e ter a característica de amar e respeitar o outro.

\section{REFERÊNCIAS}

ABRIC, J. C. Abordagem estrutural das RS. In: MOREIRA, A. S. P.; OLIVEIRA, D. C. de (Orgs.). Estudos Interdisciplinares de Representação Social. 2. ed. AB Editora. 2000 .

BRASIL, Constituição da República Federativa do Brasil. Brasília, DF: Senado Federal, 1998.

- Resolução $\mathbf{n}^{\mathbf{0}}$ 4. Institui Diretrizes Operacionais para o Atendimento Educacional Especializado na Educação Básica, modalidade Educação Especial. Brasília: MEC, 2009

Decreto $\mathbf{N}^{\mathbf{0}}$ 7.611. Dispõe sobre a educação especial, o atendimento educacional especializado e dá outras providências. Brasília: MEC, 2011.

Lei $\mathbf{N}^{\mathbf{0}}$ 12.796. Altera a Lei $\mathrm{n}^{\mathrm{o}} 9.394$, de 20 de dezembro de 1996, que estabelece as diretrizes e bases da educação nacional, para dispor sobre a formação dos profissionais da educação e dar outras providências. Brasília: Senado Federal, 2013.

Lei 13.146. Institui a Lei Brasileira de Inclusão da Pessoa com Deficiência (Estatuto da Pessoa com Deficiência). Brasília: Senado Federal, 2015.

CORREIA, Vasti Gonçalves de Paula. A comunicação Alternativa e ampliada no contexto escolar: Uma via de acesso à inclusão de alunos com paralisia Cerebral. In.: ORRU, Silvia Ester (Org.). Estudantes com Necessidades Educacionais Especiais: Singularidades e desafios na prática pedagógica inclusiva. Rio de Janeiro: Wak Editora, 2012. 
NÓBREGA, Sheva Maia; COUTINHO, Maria da Penha de Lima. O teste de associação livre de palavras. In.: COUTINHO, Maria da Penha de Lima [et al] Representações sociais: Abordagem interdisciplinar. João pessoa: Ed. Universitária- UFPB, 2003.

DOISE, W. Representations et relations entre groupes. In.: MOSCOVICI, S. Introctucion à la Psychologie Sociale. Paris: Larousse, 1995.

GONÇALVES, Arlete Marinho. A estrutura e o conteúdo das representações sociais elaboradas por docentes da escola pública acerca do projeto político pedagógico. Revista Cocar, V. 6, $\mathrm{n}^{\circ}$ 12, 2012. Disponível em: http://paginas.uepa.br/seer/index.php/cocar/article/view/231. Acesso 12 de jul. 2015.

JODELET, D. Representação sociais: um domínio em expansão. In: As representações sociais. Tradução: Lilian Ulup. Rio de Janeiro: EDUERJ. 2001.

MACHADO, Laeda Bezerra; ANICETO, Núcleo Central e Periferia das representações sociais de ciclos de aprendizagens entre professores. Revista Ensaio: aval. Políticas públicas e Educação, Rio de Janeiro, v. 18, n. 67, p. 345-364, abr./jun. 2010. Disponível em: http://www.scielo.br/pdf/ensaio/v18n67/a09v1867.pdf. Acesso em: 04 de jul. 2015.

MOSCOVICI, S. Representações Sociais: investigações em psicologia social. Rio de Janeiro: Vozes, 2003.

OLIVEIRA, C. D.; MARQUES S. C.; TOSOLI, A. M. Analise das evocações livres: uma técnica de análise estrutural das representações sociais. In: MOREIRA, A. P. et al. (Org.). Perspectivas teórico-metodológicas em representações sociais. João Pessoa: Ed. da UFPB, 2005.

SÁ, C. P. A construção do objeto de pesquisa em representações sociais. Rio de Janeiro. EDUERJ, 1998.

Núcleo Central das representações Sociais. Petrópolis: vozes, 2002

VERGÈS, P. Manuel Ensemble de programmes permettant L' Analyse des evocations: EVOC 2000. Versão 5 Avril, 2002. O programa Windows (Delfos 2 e 3) foi realizado por Stéphane SCANO e por Christian JUNIQUE (MMSH). Os programas Tubo-Pascal foram realizados por PierreVERGÈS (LÂMINAS).

VYGOSTSKY, L.S. A formação Social da mente. São Paulo: Martins Fontes, 1994. 